\title{
Smart Duster-An Automatic Board Cleaning Device
}

\author{
Hithashree $\mathrm{C}^{1}$, Bharath $\mathrm{M} \mathrm{K}^{2}$, Harshith ${ }^{3}$, Ila Mohan ${ }^{4}$, Dr Rashmi $\mathrm{S}^{5}$ \\ ${ }^{1234}$ Students, VVCE, Mysore, India. ${ }^{5}$ Associate professor, VVCE, Mysore, India. \\ ${ }^{5}$ Department of Electrical and Electronics Engineering \\ Vidyavardhaka College of Engineering \\ Mysore, India \\ Email : hithashreec98@gmail.com, bharathmk.05@gmail.com, itsharshithgowda94@gmail.com, \\ ilamohan29@gmail.com,rashmi.s@vvce.ac.in
}

\begin{abstract}
A trending development in technologies demands for the higher performance machine to satisfy human and market needs. In today's scenario, the world demands everything to be automated especially in the field of medical science, engineering and teaching fields etc. It is often seen that the boards which are used in schools and colleges are approximately 20 feet wide. And these chalkboards when completely written takes more than a minute to clean it manually. If a class continue for about one hour then about $10-12 \%$ time will be wasted in cleaning such a big board with a tiny duster. And the chalk dust obtained after erasing the board is also hazardous for human health. The "Automatic Board Cleaning Device" is a spectacular replacement of traditional duster. This project was selected by us to provide some comfort for teachers while cleaning the chalkboard. This automatic board cleaning system uses the aluminium track and wheels mechanism that moves horizontally for cleaning the chalkboard with the help of DC geared motors. It is also modified by adding a sprinkler and blower for wet wiping the board. Implementing this technique reduces the time consumption in cleaning the chalkboard manually as it can clean the board within a few seconds.
\end{abstract}

Keywords-Aluminum track and wheel mechanism, Automatic Board cleaning device, Sprinkler and blower.

\section{INTRODUCTION}

For teaching purpose generally, boards are used. Chalkboard is the basic thing in a classroom for effective learning. Nowadays even the classrooms are automated as smart classrooms then why not a smart duster? The traditional way of cleaning the chalkboard using a duster causes stress to the board cleaner. The chalk piece is principally composed of Calcium Carbonate ( $\mathrm{CaC03})$. This irritates the eyes and skin infections. Also, it causes breathing problem for some people who are allergic to the chalk dust. The effectiveness of a teacher or lecturer using blackboard in his presentation to a class or audience is materially exaggerated to his disadvantage as he stops the blackboard work from time to time to erase it [7]. Using technologies can help us to overcome these kinds of problems.

Our main intention is to implement a new technology that cleans the chalkboard without requiring any manual work and help us to overcome the problems as mentioned above. In this system for cleaning the chalkboard, a duster is mounted on the aluminium track for horizontal movement on the board and has a motor mounted by the side of the track that is mechanically unified to a drive assemblage. The aluminium track and wheels mechanism convert the rotator motion of the motor into linear motion of wheels. Thus the duster moves on the board and carries out the erasing operation by the throw of a switch. Implementation of this technology saves time and energy.

A few automatic board cleaners have been designed and also been implemented in some places. The earlier used method was the rope and pulley mechanism which comforted the teachers in some way but the dilemma of time consumption was not solved. The rapid growth in technologies requested for better performance machine which can fulfil the human demand and market. This suggested new improvements that clean the board easily and conveniently [9].

\section{LITERATURE REVIEW}

In [1], the author proposed a model of a board cleaning device that uses a DC geared motor along with a switch, guideways and wheels. In his model, he connected a gearbox with the motor shaft to another gear. These gears movement rotated the wheel axel. Simultaneously the superior and inferior wheels start revolving. Thus the duster cleans the board automatically in a minimum period.

In [2], the author proposed a study and designed his project by using a serial manipulator. The serial manipulator used in his model was un-portable and reasonably priced to overcome the problem of using expensive duster that was attached to the board or adjoining wall.

In [3], the automatic whiteboard cleaning system consists of ARDUINO, relay, DC gear motor, supports and a cleaner bar. In this model, the node MCU has been used for controlling the board using IOT based mobile application (blynk). The ARDUINO provides a signal to the relay at a specific time interval. To drive the motor, they have used four-channel relays of which each motor has two relays, one for forward and other for the reverse direction. Hence the motor is made to rotate in both clockwise and anti-clockwise direction. 
In [4], the author projected a system that overcomes the disadvantage of the usage of an earlier board cleaner that had a belt pulley. His project had a tiny, high rpm motor that rotates the plate which holds the duster and PIC microcontroller. The collected dust was bleached and recycled to make a new chalk piece.

In [5], the author proposed a model that consists of AVR microcontroller because of which the model is very easy to crest the controlling circuit which enables us to create the machine easily. He says that it is possible to fabricate the circuit using Atmega16, Atmega-128 and other chips. Besides this, the tool work needed and the materials used are also simple and not very costly.

In [6], a board cleaner system was proposed by the author to interface the motorized aspects of erasing the board involuntarily with microcontrollers. He uses a PIC microcontroller for the same purpose and the duster was placed in the midsection of the board to move the duster towards any side of the board easier and less time-consuming.

\section{Proposed Methodology}

The main purpose of this chalkboard duster is to provide an attachment in the form of a power-determined erasing system for blackboards that can be placed into action by placing a switch[1]. The requisite hardware components are as follows,

1. Chalkboard (Green or White)

2. Aluminium track

3. Nylon balls

4. DC geared motor

5. Duster

6. Wheels

\section{ARDUINO}

The cleaning unit consists of the aluminium track, track wheels, green or whiteboard, duster material etc. Track and wheel system consists of nylon balls which move inside the aluminium track which is ' $\mathrm{C}$ ' shaped. Duster material is an important part of the project to clean the board. The green board is enclosed within an aluminium track and wheel arrangement for cleaning with the help of the DC motors.

With the help of cable wire, the motors drive the wheel that begins to wound as the motor rotates and draws the wheel that is connected to another end of the cable. On the aluminium track holding the connecting strip with the duster connected to it by bearing arrangement, it transforms the rotary motion wheel into linear motion. The roller or the wheel rotates at high torque which is produced by the use of a geared motor. This ensures a null gap between the board and the erasing apparatus [9].

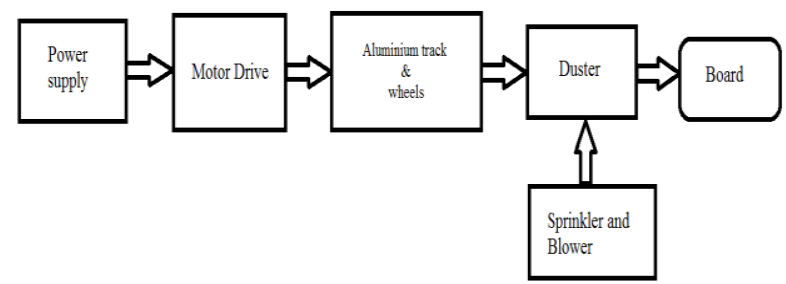

Figure 1 Block diagram of the proposed model

We are going to use two motors- one motor is used to erase the board in the forward direction and another motor used to erase the board backwards that is to get back the duster. In this system, the DPDT switch and the limit switch will also play a minor role [10]. In the backlink aluminium track, the grease mechanism is used to change the clearance between the aluminium track and the wheel.

When supply is on, 'SMPS' converts $230 \mathrm{~V}$ AC to $24 / 12 \mathrm{~V}$ DC. Thus ARDUINO passes the signal to the driver module which is DC. Motor runs in the speed of 80 to $100 \mathrm{rpm}$. Also remote is made in such a way that all the per cent of cleaning the board are programmed in it. Motor runs in both forward and reverse direction. Small size sprinkler and fans are provided to clean board once in a day. A cylinder shape connecter is used to wind the rope as the motor starts to run. The rope which is connected to driving wheels operates duster unit in both clock and anti-clockwise direction. ARDUINO has been programmed to clean quarter, half and full board.

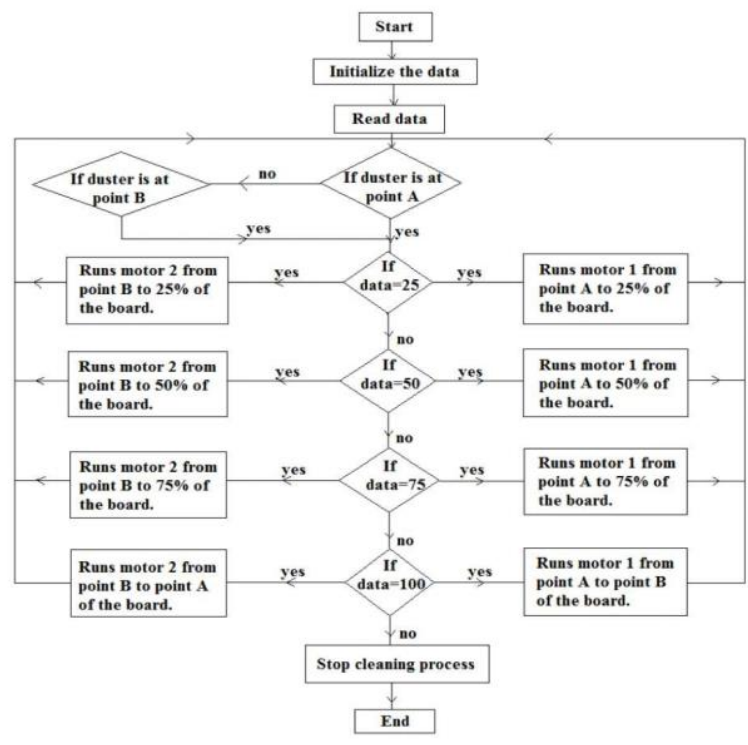

Figure 2 Flowchart showing the operation of the project 
The controlling device uses the ARDUINO UNO, which is a microcontroller board based on the ATmega328. It is a great tool for increasing interactive artefacts that can be used to take inputs from a variety of switches or sensors and to monitor lights, motors and other outputs. The board is fitted with 20 digital input/output pins, 6 analogue inputs, a $16 \mathrm{MHz}$ ceramic resonator, a USB link, a power jack, an ICSP header and a reset button (of which 6 can be used as PWM outputs). One of the special features [11] is its ease of programmability.

The proposed project is modified further with the arrangement of water sprinkler and fans. Two water pumps are attached on either side of the duster bar to sprinkle the water and wet wiping of the board. The fans of $12 \mathrm{~V}$ rating are fitted along with the duster so that as the water pump sprinkles the water on the board, the duster is made to move and simultaneously the fans blow air to dry the board. Whiteboard does not require the sprinkler system.

\section{LAYOUT OF THE PROJECT}

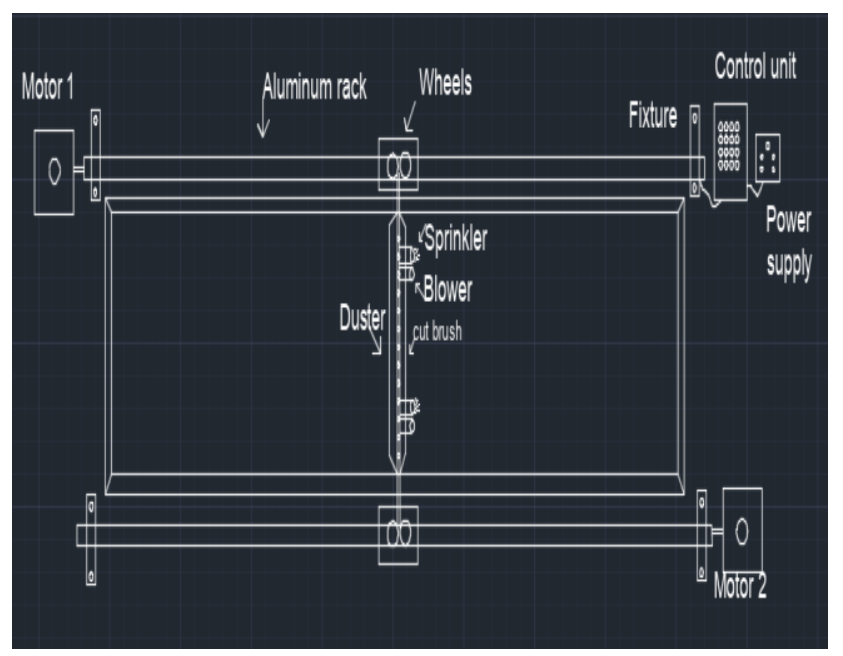

Figure 3 The layout of the proposal

The specifications of the materials used in our project is shown below

\begin{tabular}{|c|c|c|}
\hline PARTICULARS & SPECIFICATION & QUANTITY \\
\hline DC MOTOR & $100 \mathrm{RPM} / 24 \mathrm{~V}$ & $2 \mathrm{NOS}$ \\
\hline SMPS & $230 / 24 \mathrm{~V}$ & $1 \mathrm{NO}$ \\
\hline $\begin{array}{c}\text { ARDUINO } \\
\text { UNO }\end{array}$ & - & $1 \mathrm{NO}$ \\
\hline USB CABLE & - & $1 \mathrm{NO}$ \\
\hline
\end{tabular}

Vol. 4 (3), September 2020, www.ijirase.com

\begin{tabular}{|c|c|c|}
\hline $\begin{array}{c}\text { ALUMINUM } \\
\text { RACK }\end{array}$ & $34 \mathrm{FT}$ & - \\
\hline FAN & $24 \mathrm{~V}$ & $4 \mathrm{NO}$ \\
\hline $\begin{array}{c}\text { WATER } \\
\text { PUMP }\end{array}$ & $12 \mathrm{~V}$ & $2 \mathrm{NO}$ \\
\hline
\end{tabular}

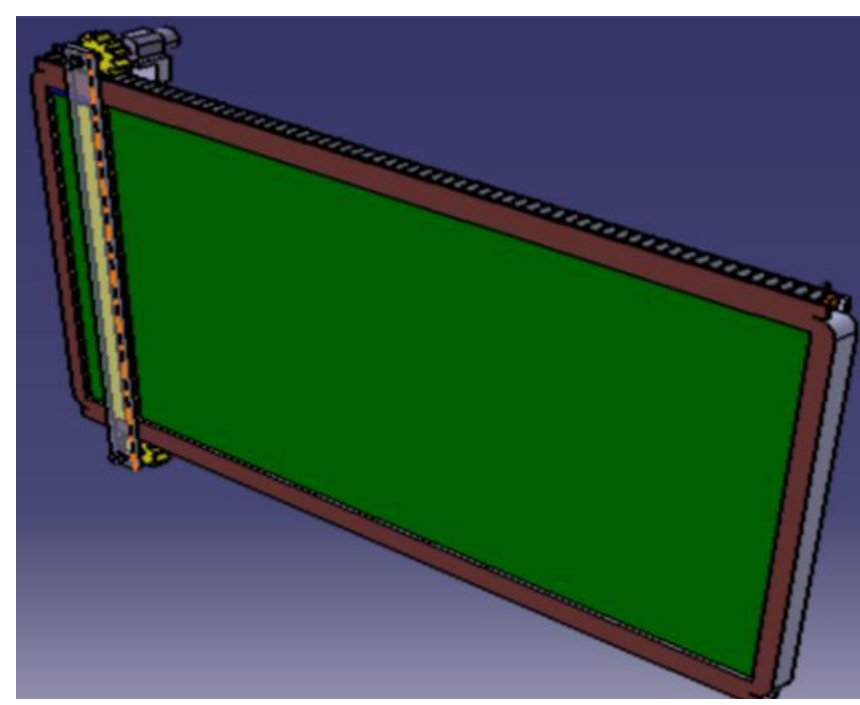

Figure $43 D$ view of the project

\section{SPEED VS TORQUE}

Torque is the rotational equivalence of linear force whereas the speed is the measurement of the distance covered in a unit time. The relation between torque and speed is inversely proportional to each other. The reason is the ability to generate torque diminishes with enhancing speed. As the increase in speed results in low torque and the decrease in speed generates elevated torque, the actual speed that can hold the load can be known [12].

\section{TIME OF OPERATION}

The time consumption for the entire process to be done is one of the most important factors to be considered. The user should not be bored by the machine operation if it takes more time to erase the board. The result of the operation of the designed machine should be effective and comfortable to the user. Keeping this point of view, the project is designed according to the distance it should cover within less time. If we consider the length of the board to be 20 feet long the time consumption in cleaning the board is as follows: 


\begin{tabular}{|c|c|c|c|}
\hline OBSERVATION & $\begin{array}{c}\text { TIME } \\
\text { TAKEN }\end{array}$ & MOTOR 1 & MOTOR 2 \\
\hline $25 \%=5$ feet & $4 \mathrm{sec}$ & Forward & Reverse \\
\hline $50 \%=10$ feet & $8 \mathrm{sec}$ & Forward & Reverse \\
\hline $75 \%=15$ feet & $12 \mathrm{sec}$ & Forward & Reverse \\
\hline $100 \%=20$ feet & $16 \mathrm{sec}$ & Forward & Reverse \\
\hline
\end{tabular}

\section{CONCLUSION}

The proposed technique makes human work easier and the problem of swinging the hand up and down to clean the board can be overcome. It is simple in construction and operating. The health problems caused by chalk dust can be reduced. Also, the maintenance cost is less. There is no problem of holding the duster again and again to clean the board. Automatic wiping off the board has a good effect on human and also runs smoothly compared with manual wiping. This technique can be implemented in any institution that uses chalkboards.

\section{REFERENCES}

[1] Mr.Tumpala Uma Santhosh, Ch.Venkata Anvesh, R Art Babu, A.Vinutha, "Design and Fabrication of an Automatic Black Board Cleaner" in 2016 International Journal of Latest Research in Engineering and Technology (IJLRET), volume 02, Issue-12, December 2016, pp.15-35.

[2] Sahib Singh Dhanjal, Prof. D.K.Pratihar, "Design and Development of Board Cleaning Serial Manipulator" in 2015 IEEE UPCON 2015.

[3] M.Suresh, Dr.R.Meenakumari, Dr.P.S.Raghavendran, V.Gowrishankar, P.Karthikeyan, V.Surendar, C.Jagan, N.Krishna Prashant, "Design and Development of Automatic Whiteboard Cleaner for Effective Cleaning Mechanism using ARDUINO" in 2018 International Journal of Innovative Research in Electrical, Electronics, Instrumentation and Control Engineering, volume 6, Issue9, September 2018.

[4] Dr.S.Poornachandra, V.S.Jagadhish, B.Vivekanandhan, "Automated Board Duster" in 2018 International Journal for Research in Applied Science and Engineering Technology (IJRASET), volume 6, Issue-3, March 2018.

[5] Md.Mayn Uddin, Naymuzzaman Akanda, Md.Golam Kibria, "An Integrated Cleaning Approach of Automatic Whiteboard" in 2017 International Research
Journal of Engineering and Technology (IRJET) volume 04, Issue-12, December 2017.

[6] Vivek D.Ugale, Aishwarya Marathe, Tiwari Ashutosh, Nilesh Ugale, "Automatic Blackboard Eraser" in 2015 International Journal of Advanced Research in Electronics and Communication Engineering (IJARECE) volume 4, Issue-4, April 2015.

[7] Sonia Akhter, Anindo Saha, Md.Rayhan Parvez Koushik, Md.Asaduzzaman, Razoana Islam Shorna, Md.Moudud Ahmed, "Automatic Whiteboard Cleaner using Microcontroller based Rack and Pinion Mechanism" in 2015 International Conference on Mechanical Industrial and Materials Engineering 2015(ICMIME 2015) in December 2015, paper ID : IE-52.

[8] Chirag Shah, "Automated Board Eraser" in 2015.

[9] M Agalya Devi, R Aruna, M Arrthi, A Jeevalekha, A Mariyammal, "Microcontroller Based Handy Free Duster for Classroom" in 2017 Asian Journal of Applied Science \& Technology (AJAST) volume 1, Issue-2, pages 40-42, March 2017.

[10] Gaurav Gangurde, "Design and Development of Board Cleaning System" in 2016 International Journal of Research and Scientific Innovation (IJRSI) volume 3, Issue-3, March 2016.

[11] S. Joshibaamali And K. Geetha Priya,"Automatic Duster Machine", in 2015 International Journal Of Emerging Technology In Computer Science \& Electronics (IJETCSE) volume 13, Issue 1, March 2015.

[12] Mr. Sunil R. Kewate, Mr Inzamam T. Mujawar, Mr. Akash D. Kewate, Mr.Hitesh R. Pant, "Development of New Smart Design to Erase the Classroom Blackboard of Schools/Colleges", IOSR Journal of Mechanical and Civil Engineering (IOSR-JMCE). 